\title{
DELINEAMENTO SEMI-DETALHADO DE SOLOS EMPREGANDO AEROFOTOS NÃO-CONVENCIONAIS NA SUB-BACIA PALMITAL - RIO TURVO SUJO, MG
}

\author{
Marcus Manoel Fernandes ${ }^{1}$, João Carlos Ker $^{2} \&$ Sérvulo Batista de Rezende²
}

\begin{abstract}
RESUMO
Com o objetivo de caracterizar os solos da sub-bacia Palmital e testar aerofotos não-convencionais foram descritos e coletados perfis e amostras extras de solos, além da obtenção das aerofotos. As amostras foram submetidas a análises física, químicas e mineralógica. As classes de solos são: Latossolos VermelhoAmarelos Distróficos (interflúvios tabulares, topos das elevações e encostas côncavas), Latossolos Amarelos Distróficos (vertente convexa), Cambissolos Háplicos Tb Distróficos latossólicos (conformação íngreme), Argissolos Vermelho-Amarelos Eutróficos (terraço), Argissolos Vermelho-Amarelos Eutróficos + Cambissolos Háplicos Tb Distróficos latossólicos (rampas coluviais) e Latossolos Vermelho-Amarelos Distróficos + Cambissolos Háplicos Tb Distróficos latossólicos + Latossolos Amarelos Distróficos (vertentes ravinadas). A maioria dos solos é de baixa fertilidade natural, apresentam teores de bases trocáveis e CTC muito baixos, $\mathrm{pH}$ ácido e alta saturação de alumínio. Os difratogramas de Raios-X indicam uma grande similaridade de composição mineralógica; caulinita, goethita e gibbsita estão sempre presentes. As aerofotos não-convencionais apresentaram excelente nitidez e efeito estereoscópico e contribuíram sobremaneira na identificação das unidades para o delineamento semi-detalhado dos solos.
\end{abstract}

Palavras-chave: solos, aerofotos não-convencionais, sub-bacia

\begin{abstract}
In order to characterize the soils of the sub-basin Palmital and test airphotos non-conventional were described soil profiles and extra samples, besides the obtainance of airphotos. The samples were physically, chemistry and mineralogically analysed. The soils classes are: Distrophics Red Yellow Latosols (small plateaux, summits and concave slopes), Distrophics Yellow Latosols (convexe slopes), Distrophic Latosol Cambic (on steep slopes), Eutrophic Red Yellow Podzolic + Distrophic Latosol Cambic (accumulation glacis) and Distrophics Red Yellow Latosols + Distrophic Latosol Cambic + Distrophics Yellow Latosols (dissected slopes). The most of the soils are of low natural fertility, presenting available exchanges base and CEC (cation exchange capacity) very lows, acid $\mathrm{pH}$ and high alluminum saturation. The X-rays diffractograms indicate a great similarity of mineralogy composition; caolinite, goethite and gibbsite are always present. The non-conventional airphotos revealed to be of excellent clearness and stereoscopic effect and had good contribution in the identification of units for half-detailed mapping soil.
\end{abstract}

Keywords: soils, non-conventional airphotos, sub-basin.

\section{INTRODUÇÃO}

Para um melhor uso dos recursos naturais não só é necessário identificar-se os ambientes de uma mesma região, como também desenvolver técnicas conservacionistas mais adequadas ao uso dos solos de acordo com a sua aptidão. Como esses cuidados não se limitam a uma única propriedade rural, a melhor alternativa parece ser, então, considerar a sub-bacia hidrográfica como unidade de estudo.

As bacias hidrográficas são uma unidade natural por emoldurarem, num conjunto único, os fenômenos que ocorrem no seu interior (Rezende, 1986). Uma bacia hidrográfica possui um ciclo hidrológico próprio, regido por fatores climáticos, pedológicos, geológicos, topográficos e vegetativos específicos (Resck \& Gomes, 1995).

Rocha (1991) mencionou que subdividir as bacias hidrográficas em sub-bacias e microbacias tem sido de grande valia em trabalhos de campo para planejamento de recuperação ambiental.
Um aspecto indispensável para o planejamento e o manejo de recursos naturais é a disponibilidade de informações atuais e precisas (Disperati, 1991). Essas informações podem ser obtidas pela interpretação de fotografias aéreas, que é um recurso básico e constitui uma técnica capaz de infinitos refinamentos (Carver, 1988).

Desde a década de 1950, inúmeros estudos foram realizados visando à obtenção de fotografias aéreas por meio de câmaras fotográficas convencionais do tipo 35 e $70 \mathrm{~mm}$. Tal procedimento já está solidamente estabelecido nos Estados Unidos, Canadá, Austrália e alguns países europeus.

A obtenção de aerofotos convencionais tem custo elevado; este fato torna inviável seu emprego em pequenas áreas. Para viabilizar os estudos nessas pequenas áreas foi desenvolvida uma técnica de obtenção de aerofotos não-convencionais, com resultados já comprovados (Cavalcanti, 1994). 
São denominadas aerofotos não-convencionais porque o processo de obtenção não faz uso de câmaras aerofotogramétricas. As fotos são adquiridas com câmaras fotográficas adaptadas a um suporte. É um meio suplementar de obter as fotografias aéreas.

A grande perspectiva do uso de aerofotos nãoconvencionais, entre outros aspectos, refere-se à acessibilidade e ao baixo custo de aquisição das fotografias, devido ao uso de equipamentos mais simples, em comparação com as aerofotos obtidas com câmaras aerofotogramétricas.

Este trabalho tem como objetivo caracterizar os solos da sub-bacia Palmital e testar as aerofotos não-convencionais empregadas como suporte ao delineamento semi-detalhado de solos.

\section{MATERIAL E MÉTODOS}

A área, objeto do presente trabalho pertence à bacia hidrográfica do rio Turvo Sujo, afluente do rio Turvo Limpo. Encontra-se nas proximidades de Viçosa, Estado de Minas Gerais / Brasil (Figura 1).

A sub-bacia Palmital localiza-se na porção média da bacia do rio Turvo Sujo, entre os meridianos de $42^{\circ} 50^{\prime}$ e $42^{\circ} 52^{\prime}$ e entre os paralelos de $20^{\circ} 49^{\prime}$ e $20^{\circ} 51^{\prime}$, com cerca de $175 \mathrm{ha}$. A altitude média é de $750 \mathrm{~m}$ e encontrase a $11,6 \mathrm{Km}$ de Viçosa pela rodovia que dá acesso a Paula Cândido.

A geologia local insere-se na Província Mantiqueira. Esta unidade reúne os seguintes litotipos (COMIG / CPRM, 2003):

$\rightarrow$ Complexo Piedade: ortognaisse TTG (TonalitoThrondjemito-Granodiorito) com frequentes intercalações de supracrustais e, localmente, de ortognaisse do embasamento mesoarqueano.

$\rightarrow$ Complexo Juiz de Fora: ortognaisse enderbítico com frequentes intercalações de granulito básico e remanescentes de ortognaisse do embasamento mesoarqueano.

O relevo é dominantemente forte ondulado e montanhoso ("Mar de Morros"), com encostas de perfil convexo-côncavo embutidos em vales de fundo chato, formados por terraços e leitos maiores, onde meandram pequenos córregos (Corrêa, 1984).

O clima enquadra-se no tipo Cwa (Inverno seco e verão chuvoso), da classificação de Köppen, caracterizado pela temperatura média anual do mês mais quente superior a $22^{\circ} \mathrm{C}$ e a do mês mais frio inferior a $18^{\circ} \mathrm{C}$.

\section{Obtenção das aerofotos não-convencionais}

As fotografias aéreas não-convencionais foram obtidas por meio de um processo desenvolvido por Rezende (1986). Esse processo consta de um suporte que serve de base para o equipamento fotográfico. $\mathrm{O}$ suporte é preso junto aos orifícios abertos na fuselagem da aeronave CESSNA 182-Skylane. Em seguida, as câmaras fotográficas de qualidade profissional, já com filmes, são fixadas ao suporte e conecta-se o intervalômetro previamente programado. Previamente, também, é inserido ao GPS (Global Positioning System), acoplado à aeronave, todos os dados referentes ao planejamento das linhas de vôo.

Inicialmente realizou-se o planejamento de vôo, no qual levou-se em consideração os critérios adotados para um aerolevantamento convencional como: recobrimento longitudinal de $60 \%$, recobrimento lateral de $30 \%$, altura efetiva de vôo, escala desejada, possíveis correções das linhas de voo etc (Aguirre, 1991; Disperati, 1991).

As aerofotos não-convencionais foram tomadas na escala aproximada de 1:20.000 e, posteriormente, ampliadas para a escala definitiva de 1:5.000. O aerolevantamento foi efetuado a uma altitude de aproximadamente $1.650 \mathrm{~m}$.

O horário para a tomada das fotografias situouse entre 9:00 e 15:00h, a fim de evitar longas sombras que pudessem diminuir a qualidade das imagens para interpretação. As fotos foram tomadas em condições de céu praticamente sem nuvens.

\section{Descrição e coleta dos perfis e amostras extras dos solos}

A descrição dos perfis e a coleta dos materiais de solos foram realizadas em trincheiras em cada um dos locais previamente selecionados, além de amostras extras (horizontes A e B), coletadas com auxílio do trado holandês (Lemos \& Santos, 1982). Após a secagem e peneiramento em malha de $2 \mathrm{~mm}$ para a obtenção da terra fina seca ao ar (TFSA), as amostras foram submetidas às análises física (granulometria), químicas (cálcio, magnésio e alumínio trocáveis; fósforo e potássio disponíveis; hidrogénio + alumínio; carbono orgânico; pH em $\mathrm{H}_{2} \mathrm{O}$ e $\mathrm{KCl} 1$ mol.L-1; teor de óxidos pelo ataque sulfúrico e extração dos óxidos de ferro com ditionito-citrato-bicarbonato de sódio) e mineralógica (difratometria de Raios-X) dos solos (EMBRAPA, 1997).

\section{Delineamento do mapa semi-detalhado dos solos}

A área da sub-bacia foi delimitada com auxílio das aerofotos com escala aproximada 1:5.000 e de carta topográfica 1:50.000, referente à Folha SF-23-X-B-V-3 (FIBGE, 1979).

A partir das fotografias aéreas e com um estereoscópio de espelhos, procedeu-se à fotointerpretação para a confecção do delineamento dos solos. Para tal, realizouse uma fotoanálise preliminar da área, demarcandose em primeiro lugar todos os padrões fisiográficos visualizáveis. As unidades fisiográficas identificadas foram transpostas para uma base cartográfica na mesma escala, constituindo um mapa fisiográfico destinado ao apoio dos trabalhos de campo.

Com o mapa fisiográfico resultante da fotoanálise, efetuou-se uma prospecção intensa da área, com a finalidade de identificar as principais correlações entre as unidades fisiográficas e as ocorrências das unidades de solo.

Na classificação dos solos usaram-se as normas, 


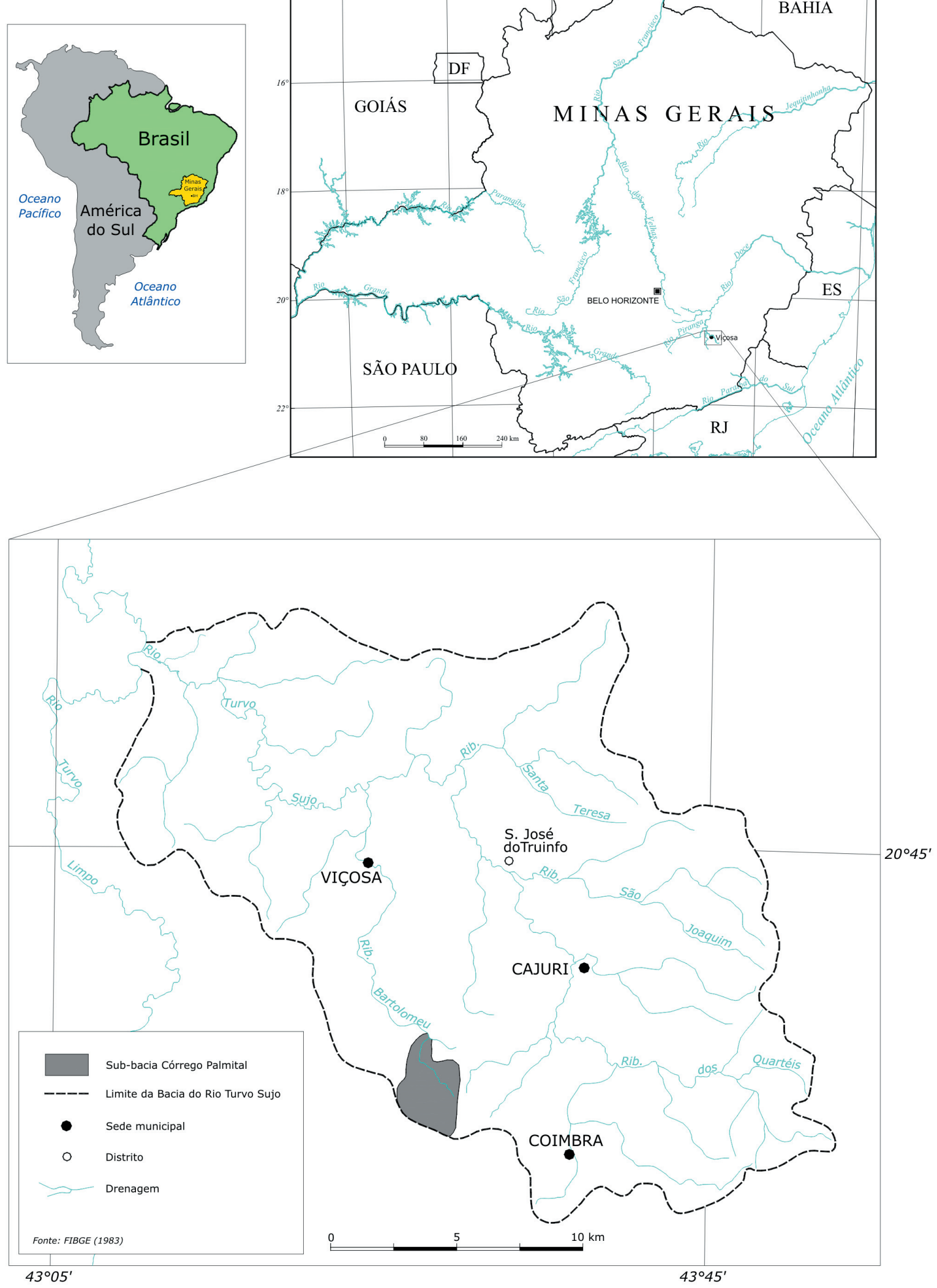

Figura1. Localização da sub-bacia Palmital (Viçosa, $M G$ ). 
critérios e nomenclatura preconizados pelo CNPS (Centro Nacional de Pesquisa de Solos - EMBRAPA) para solos do Brasil. Procurou-se sempre seguir os conceitos, definições e normas do referido centro (EMBRAPA, 2006).

\section{RESULTADOS E DISCUSSÃO}

As observações de campo permitem constatar e repetibilidade das formas dos interflúvios na área estudada. As conformações topo de elevação, terraço e encostas íngreme, côncava e convexa ocorrem e são comuns na sub-bacia. Essa repetibilidade das conformações está de acordo com o observado por Corrêa (1984) no Planalto de Viçosa.

A caracterização dos solos baseou-se nos resultados das análises física, químicas e mineralógicas do material coletado e teve como suporte as aerofotos não-convencionais e observações de campo.

Os Latossolos Vermelho-Amarelos Distróficos - LVAd predominam nos interflúvios tabulares, topos mais amplos das maiores elevações e nas encostas côncavas. A textura dominante varia de muito argilosa nos interflúvios tabulares a argilosa nas conformações côncavas. A cor mais amarelada deve-se ao amplo predomínio de goethita em relação a hematita, situação comum no Planalto de Viçosa (Corrêa, 1984; Carvalho Filho, 1989). Em geral, os Latossolos dos interflúvios tabulares são menos espessos que os ocorrentes nas conformações côncavas. A erosão natural talvez intensificada pela ação humana leva a um consequente rebaixamento do topo, sugerindo, de certa forma, o rejuvenescimento do Latossolo original (Rezende,
1971; Corrêa, 1984).

A vertente perfil longitudinal convexo foi caracterizada como Latossolos Amarelos Distróficos - Lad textura muito argilosa. Nessa situação podem ocorrer solos distróficos e de textura argilosa como inclusões. $\mathrm{O}$ horizonte $\mathrm{B}$ apresenta teor de $\mathrm{Fe}_{2} \mathrm{O}_{3}$ pelo ataque sulfúrico de $11,5 \mathrm{dag} / \mathrm{Kg}$. Teores de $\mathrm{Fe}_{2} \mathrm{O}_{3}$ superiores a 14\% (Carvalho Filho, 1989) e 17\% (Quinteiro, 1997) também foram encontrados nos solos da região de Viçosa e confirmam e expressividade destes solos nessa região.

Na conformação íngreme aparecem os Cambissolos Háplicos Tb Distróficos latossólicos - CXbd textura muito argilosa. Como inclusões podem ocorrer solos distróficos e solos de textura muito argilosa. A presença de fragmentos de rochas de permeio com a massa do solo, indicando um estágio pouco avançado de evolução e, somada a estrutura fracamente desenvolvida, foram as principais características do horizonte B para incluí-lo na classe dos Cambissolos. As razões principais que levaram à adjetivação estão na profundidade, baixa relação silte/argila e capacidade de troca catiônica.

No terraço constatou-se a ocorrência de Argissolos Vermelho-Amarelos Eutróficos - PVAe A moderado tetxura média/argilosa. O incremento de argila do horizonte A para o B relativamente acentuado (Figura 2 - PVAe) foi a principal razão para incluir o solo na classe dos B texturais. A pequena expressão de cerosidade e mesmo o grau moderado de desenvolvimento de estrutura foram os critérios para adjetivação câmbica.

O teor de silte mais elevado no solo de terraço pode estar relacionado com parte do material depositado ser
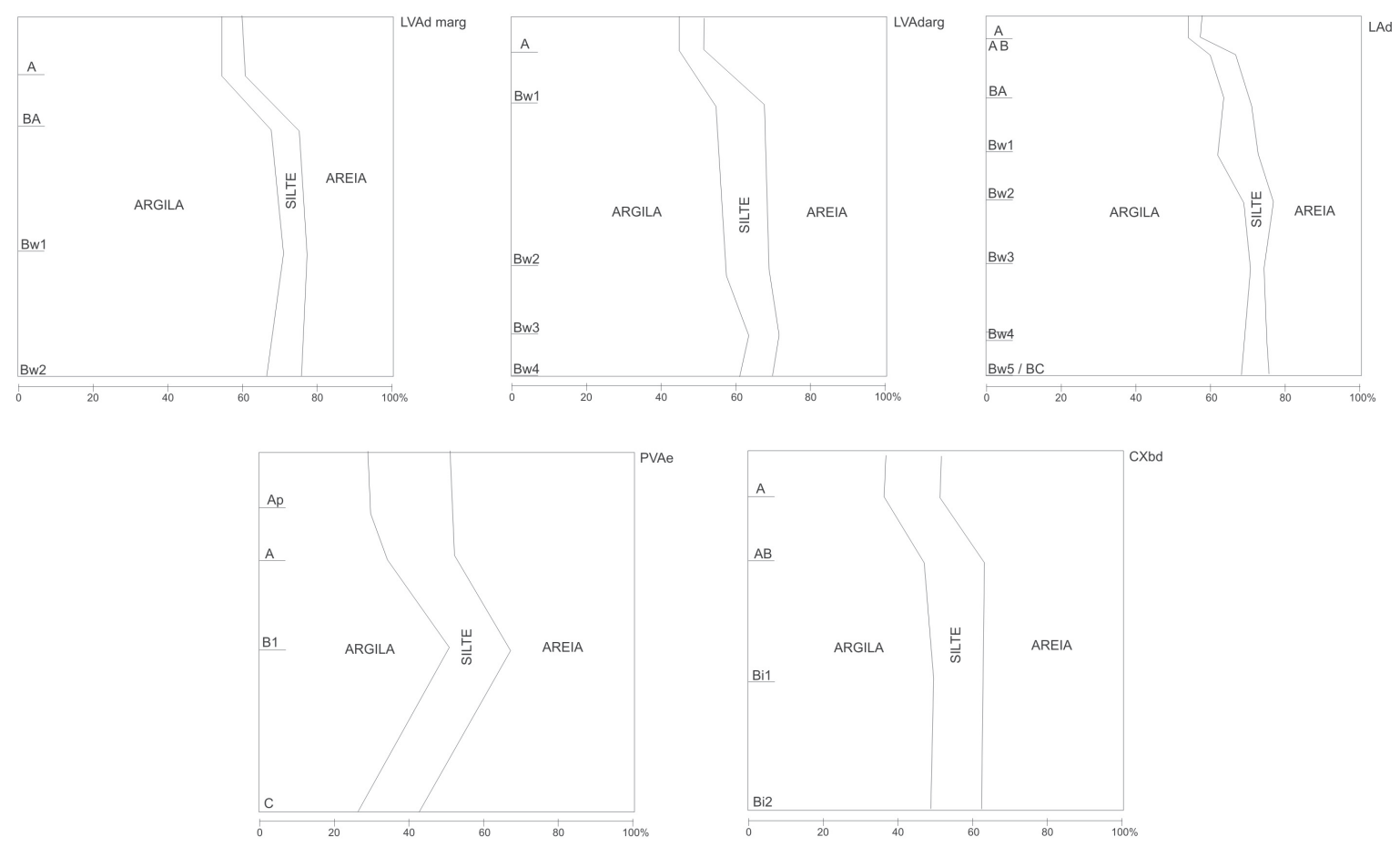

Figura 2. Esquema ilustrativo das diferentes texturas dos horizontes dos solos estudados. 


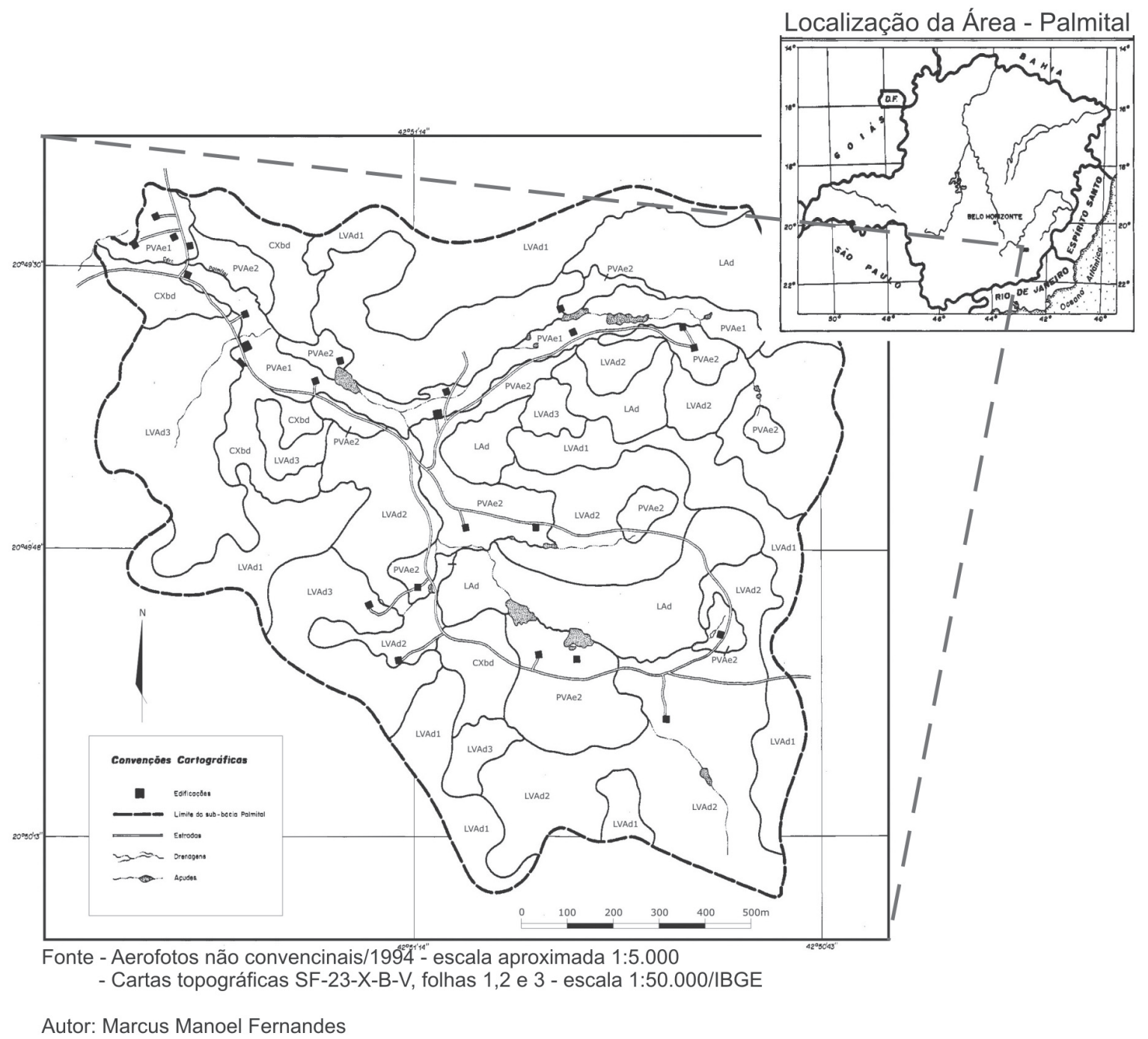

\section{LEGENDA}

LVAd1 - LATOSSOLOS VERMELHO-AMARELOS Distróficos A moderado textura muito argilosa fase floresta tropical subperenifólia relevo ondulado a montanhoso.

LVAd2 - LATOSSOLOS VERMELHO-AMARELOS Distróficos A moderado textura argilosafase floresta tropical subperenifólia relevo forte ondulado.

LVAd3 - LATOSSOLOS VERMELHO-AMARELOS textura argilosa relevo forte ondulado + CAM-BISSOLOS HÁPLICOS Tb Distróficos latossólicos textura argilosa relevo forte ondulado emontanhoso + LATOSSOLOS AMARELOS textura muito argilosa relevo forte ondulado e montanhoso todos Distróficos. A moderado fase floresta tropical subperenifólia.

LAd - LATOSSOLOS AMARELOS Distróficos A moderado textura muito argilosa fase floresta tropical subperenifólia relevo forte ondulado e montanhoso.

PVAe1 - ARGISSOLOS VERMELHO-AMARELOS Eutróficos A moderado textura média/argilosa fase floresta tropical subperenmifólia relevo plano - Inclusões: Distróficos, textura muito argilosa.

PVAe2 - ARGISSOLOS VERMELHO-AMARELOS Eutróficos textura média/argilosa relevo plano + CAMBISSOLOS HÁPLICOS Tb Distróficos latossólicos textura argilosa relevo forte ondulado e montanhoso ambos A moderado fase floresta tropical subperenifólia.

CXbd - CAMBISSOLOS HÁPLICOS Tb Distróficos latossólicos A moderado textura argilosa fase floresta tropical subperenifólia relevo forte ondulado e montanhoso - Inclusão: textura muito argilosa. 
proveniente do horizonte $\mathrm{C}$ das partes altas da paisagem. Não se descarta ainda a baixa taxa de pedogênese, além do próprio processo de sedimentação conforme realça também Naime (1988). Porém, esses valores divergem um pouco dos encontrados em solos de terraço na região de Viçosa, onde a tendência argilosa se manifesta bem mais clara (Costa, 1973; Resck, 1977; Carvalho Filho, 1989). Nesses solos, as frações areia grossa e fina são muito pouco expressivas; já no presente estudo esses valores apresentam-se bastante elevados. A comparação dos dados parece mostrar que os solos de terraço não são tão homogêneos como aparentam.

É conveniente destacar que nos terraços da região de Viçosa ocorrem tanto Argissolos Vermelho-Amarelos Eutróficos (Ker \& Schaefer, 1995) como distróficos (Costa, 1973; Resck, 1977; Carvalho Filho, 1989). Mesmo quando distróficos são relativamente mais férteis que os solos das áreas mais elevadas. A razão disso é a tabularidade da área e sua permeabilidade não muito expressiva, caracterizando um ambiente de acúmulo, portanto, mais concentrador que exportador (Corrêa, 1984; Carvalho Filho, 1989). Essas características (fertilidade e topografia) fazem com que esses solos sejam um dos mais utilizados agricolamente por pequenos agricultores da região.

Em razão da complexidade de distribuição dos solos de algumas áreas, recorreu-se à associação de solos para as rampas coluviais/deposições de pé-deencosta (Argissolos Vermelho-Amarelos Eutróficos + Cambissolos Háplicos Tb Distróficos latossólicos) e vertentes ravinadas (Latossolos Vermelho-Amarelos Distróficos + Cambissolos Háplicos Tb Distróficos latossólicos + Latossolos Amarelos Distróficos). A Figura 3 ilustra o delineamento semi-detalhado de solos da sub-bacia Palmital.

Os difratogramas de Raios-X (Figura 4) da fração argila mostram que a mineralogia dos solos estudados é bastante uniforme.

Os argilo-minerais caulinita (reflexões 0,714 e $0,358 \mathrm{~nm}$ ) e goethita (reflexões 0,418 e $0,249 \mathrm{~nm}$ ) ocorrem em proporções mais elevadas que os demais constituintes e estão presentes em todos os solos confirmados por dados de alocação, não apresentados. A gibbsita (reflexão 0,485nm) também ocorre em todos
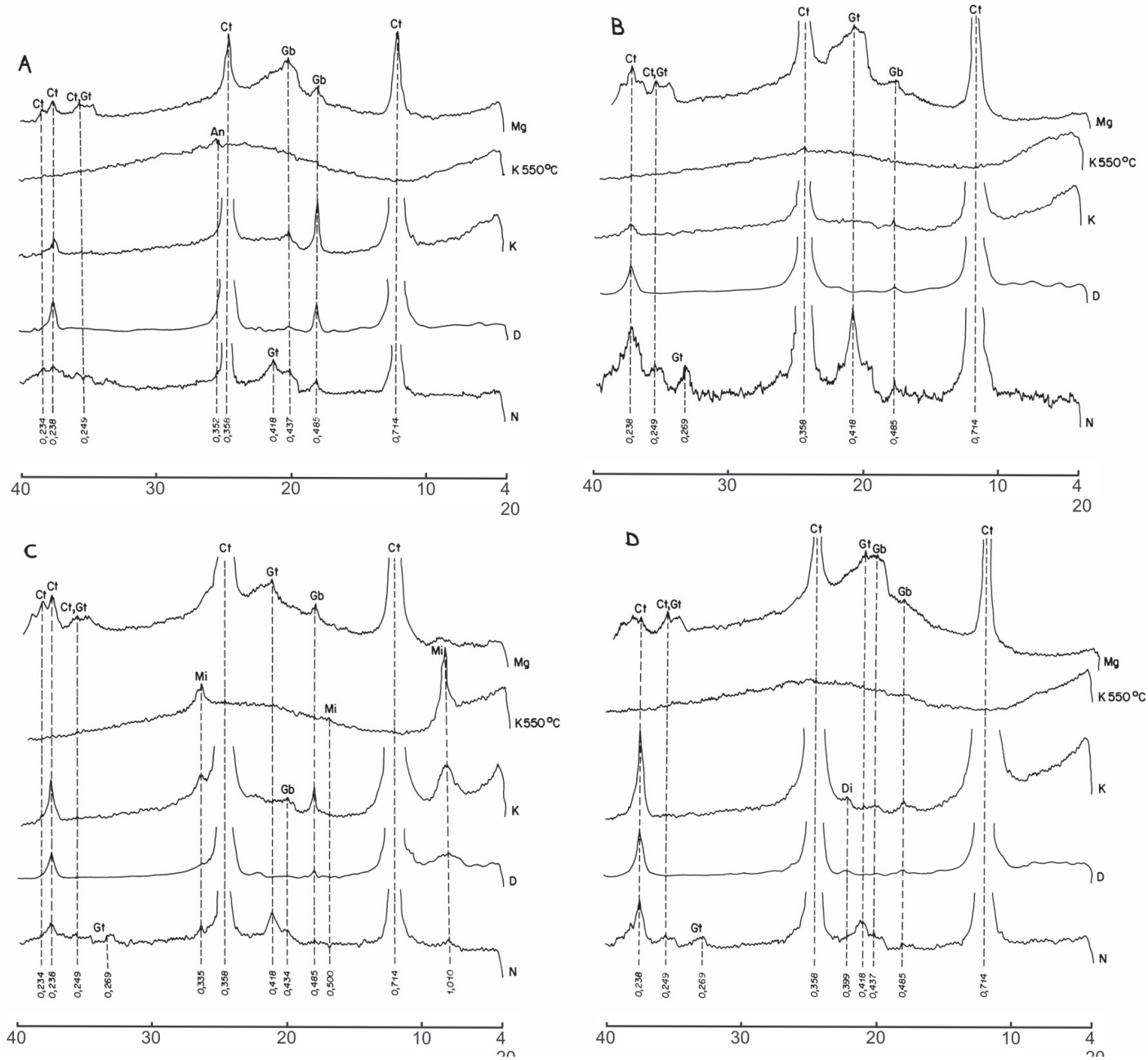

Figura 4. Difratogramas de Raios-X (lâminas orientadas) da fração argila

(A - LVAd, B - LAd, C - PVAe, D - CXbd); N-natural; D-desferrificação com DCB; K-aturação com K (com e sem aquecimento) e Mg-saturação com Mg; An - anatásio; Ct-caulinita; Di-diasporo; Gb-gibbsita; Gt-goethita e Mi-mica). 
os solos, porém em menores proporções. Picos de mica aparecem somente nos difratogramas do PVAe (reflexões $1,010 ; 0,500$ e $0,335 \mathrm{~nm})$. Foram encontrados ainda traços de anatásio (LVAd, horizonte Bw3) e diasporo (CXbd, horizonte $\mathrm{Bi} 2$ ). Ambos expressaram-se quando a fração argila foi saturada com potássio; o anatásio com aquecimento a $550^{\circ} \mathrm{C}$ e o diasporo sem aquecimento.

\section{CONCLUSÕES}

- A maioria dos solos é de baixa fertilidade natural, apresentam teores de bases trocáveis e CTC muito baixos, pH ácido e alta saturação de alumínio.

- Os difratogramas de Raios-X indicam uma grande similaridade de composição mineralógica dos solos analisados. O argilo-mineral caulinita e os óxidos goethita e gibbsita estão sempre presentes. Picos de mica aparecem somente nos difratogramas do PVAe.

- As aerofotos não-convencionais na escala aproximada de 1:5.000, obtidas especialmente para este trabalho, apresentaram excelente nitidez e efeito estereoscópico, foram de grande valia na identificação das unidades para confecção do delineamento semidetalhado de solos.

\section{REFERÊNCIAS BIBLIOGRÁFICAS}

Aguirre, A. 1991. Fotogrametria aplicada: anotações de aula. Santa Maria: UFSM, 80 p.

Carvalho Filho, A. 1989. Caracterização mineralógica, química e física de solos de duas unidades de paisagem do Planalto de Viçosa-MG. Departamento de Solos / UFV, Dissertação de Mestrado. Viçosa, 114 p.

Cavalcanti, M. A. 1994. Estratificação de ambientes, com ênfase no solo, da região de Itacaré- $B A$. Departamento de Solos / UFV, Dissertação de Mestrado. Viçosa, 73 p.

Carver, A. J. 1988. Fotografia aérea para planejamento de uso da terra. MA/SNAP/SRN/CCSA. Brasília, $77 \mathrm{p}$.

COMIG / CPRM - Companhia Mineradora de Minas Gerais / Serviço Geológico do Brasil. 2003. Mapa Geológico do Estado de Minas Gerais 1:1.000.000. CD-ROM. Belo Horizonte: COMIG / CPRM.
Corrêa, G. F. 1984. Modelo de evolução e mineralogia da fração argila dos solos do Planalto de Viçosa, MG. Departamento de Solos / UFV, Dissertação de Mestrado. Viçosa, 87 p.

Costa, L. M. 1973. Modelo de evolução das propriedades físicas e químicas dos solos de terraços fluviais, na região de Viçosa, e sua interpretação para uso agrícola. Departamento de Solos / UFV, Dissertação de Mestrado. Viçosa, 55 p.

Disperati, A. A. 1991. Obtenção e uso de fotografias aéreas de pequeno formato. UFPR/FUPEF. Curitiba, $290 \mathrm{p}$.

EMBRAPA - Empresa Brasileira de Pesquisa Agropecuária. 1997. Manual de Métodos de Análise de Solo. Brasília: EMBRAPA Produção de Informação; Rio de Janeiro: EMBRAPA Solos, 212 p.

EMBRAPA - Empresa Brasileira de Pesquisa Agropecuária. 2006. Sistema Brasileiro de Classificação de Solos. Brasília: EMBRAPA Produção de Informação; Rio de Janeiro: EMBRAPA Solos, $306 \mathrm{p}$.

FIBGE - Fundação Instituto Brasileiro de Geografia e Estatística. 1979. Cartas do Brasil - Escala 1:50.000, folha SF-23-X-B-V3. Rio de Janeiro.

Ker, J. C. \& Schaefer, C. E. 1995. Roteiro da excursão pedológica Viçosa-Sete Lagoas. UFV/SBCS. Viçosa, 46 p. (mimeografado).

Lemos, R. C. \& Santos, R. D. 1982. Manual de descrição e coleta de solo no campo. SBCS/SNLCS. Campinas, $46 \mathrm{p}$.

Naime, U. J. 1988. Caracterização de solos de terraços nas Zonas da Mata e Rio Doce, Minas Gerais. Departamento de Solos / UFV, Dissertação de Mestrado. Viçosa, 76 p.

Resck, D. V. S. 1977. Determinação da erodibilidade de um Podzólico Vermelho-Amarelo Câmbico distrófico fase terraço, localizado na Zona da Mata (MG), utilizando o simulador de chuva. Departamento de Solos / UFV, Dissertação de Mestrado. Viçosa, 88 p.

Resck, D. V. S. \& Gomes, J. F. M. 1995. Planejamento agropecuário a nível de microbacias hidrográficas na região dos Cerrados. In: Simpósio sobre o Cerrado. Brasília, 1995. Anais... Planaltina, EMBRAPA/CPAC, p. 198-222.

Rezende, S. B. 1971. Estudo de crono-toposseqüencia em Viçosa. Departamento de Solos / UFV, Dissertação de Mestrado. Viçosa, $71 \mathrm{p}$.

Rezende, S. B. 1986. Levantamento de solo e uso atual, erosão e cobertura vegetal de três microbacias, no vale do rio Turvo Sujo com a utilização de aerofotos não-convencionais. Impr. Univ. / UFV. Viçosa, 13 p. (projeto de pesquisa).

Rocha, J. S. M. 1991. Manual de manejo integrado de bacias hidrográficas. UFSM (2a ed.), Santa Maria, 198 p.

Quinteiro, F. Q. L. 1997. Levantamento do uso da terra e caracterização de ambientes da bacia hidrográfica do rio Turvo Sujo, com a utilização de aerofotos não-convencionais. Departamento de Solos / UFV, Dissertação de Mestrado. Viçosa, 91 p. 